\title{
A prática da oralidade em sala de aula: a perspectiva dos professores de língua portuguesa da rede básica pública de ensino
}

\section{The practice of orality in the classroom: the perspective of Portuguese-speaking teachers in the basic public education system}

\section{La práctica de la oralidad en la clase: la perspectiva de los profesores de la lengua portuguesa en la enseñanza publica}

\author{
Érica Danielle Silva ${ }^{1}$ \\ Neluana Leuz de Oliveira Ferragini² \\ Greyce Nathany Lopes Vieira ${ }^{3}$
}

\begin{abstract}
RESUMO: O presente trabalho tem como recorte temático o domínio discursivo da prática da oralidade. Dentre as práticas previstas para o ensino de língua portuguesa nas Diretrizes Curriculares Estaduais (2008) é comum que os professores de língua portuguesa considerem a oralidade como mais informal e mais passível de erros do que a prática da escrita. Neste trabalho, fundamentado em Dolz e Schneuwly (2011) e Marcuschi (1997; 2010), a proposta é refletir sobre a importância da oralidade, enquanto prática discursiva, e, sobretudo, sobre seu ensino nas aulas de língua portuguesa. A concepção e o modo como a prática da oralidade é considerada em sala de aula foram analisados por meio de questionários aplicados a professores de Língua Portuguesa da rede básica pública de ensino. Este corpus de análise mostrou que o ensinoaprendizagem da oralidade enquanto prática discursiva é tardio e pouco realizado. Os professores demonstraram uma concepção superficial de oralidade e um trabalho que não privilegia a prática de produção oral, já que os gêneros escritos são indicados como os mais trabalhados em sala de aula.
\end{abstract}

PALAVRAS-CHAVE: Oralidade. Prática Discursiva. Ensino.

\footnotetext{
${ }^{1}$ Professora colaboradora no Departamento de Língua Portuguesa, na Universidade Estadual de Maringá.

2 Professora Adjunta na Universidade Estadual do Paraná, campus de Apucarana.

${ }^{3}$ Graduada em Letras Português, pela Universidade Estadual do Paraná, campus de Apucarana.

Pós-graduanda (lato sensu) em Língua Portuguesa na Universidade Estadual de Londrina (UEL). (Início: 2018)
} 
ABSTRACT: The present work has as its theme the discursive domain of orality practice. Among the practices foreseen for Portuguese language teaching in Curricular Guidelines of the State of Paraná (2008), it is common for Portuguese-speaking teachers to consider orality as more informal and more error-prone than writing practice. In this work, based on Dolz and Schneuwly (2011) and Marcuschi (1997; 2010), the proposal is to reflect on the importance of orality as a discursive practice, and, above all, on its teaching in Portuguese language classes. The conception and the way the orality practice is considered in the classroom were analyzed through questionnaires applied to Portuguese language teachers in the basic teaching network. This corpus of analysis showed that the teaching-learning of orality as a discursive practice is late and little accomplished. The teachers demonstrated a superficial conception of orality and a work perspective that does not privilege the practice of oral production, since the written genres are indicated as the most worked in the classroom.

KEYWORDS: Orality. Discursive Practice. Teaching.

RESUMEM: El presente trabajo tiene como tema central el dominio discursivo de la práctica de la oralidad. Entre las prácticas previstas para la enseñanza de la lengua portuguesa en las Diretrizes Curriculares Estaduais (2008) es normal que los profesores de la lengua portuguesa consideren la oralidad como más informal y más propensa a errores que la escritura. Este trabajo, basado en Dolz y Schneuwly (2011) y Marcuschi (1997; 2010), la propuesta es reflexionar sobre la importancia de la oralidad como una práctica discursiva, y, especialmente en la enseñanza de las clases de la lengua portuguesa. El concepto y la forma de cómo la práctica de la oralidad se considera en el aula, se analizaron mediante cuestionarios aplicados a los profesores de portugués de la enseñanza publica. Este análisis expuso que la enseñanza-aprendizaje de la oralidad como práctica discursiva es tardía y poco realizada. Los profesores demostraron una concepción superficial de la oralidad y un trabajo que privilegia la práctica de la producción oral, ya que los géneros escritos son indicados como los más trabajados en el aula.

PALABRAS-CLAVE: Oralidad. Práctica Discursiva. Enseñanza.

\section{Considerações iniciais}

A fim de refletir sobre a concepção de oralidade de professores da rede básica de ensino e suas práticas pedagógicas que envolvem essa modalidade é necessário pensar teórico-metodologicamente sobre a importância da prática da oralidade no ensino de Língua Portuguesa, afinal é um dos eixos para o ensino e 
aprendizagem propostos por documentos oficiais como os Parâmetros Curriculares Nacionais - PCN (1997 e 1998) e pelas Diretrizes Curriculares do Estado Paraná - doravante DCE. Isso porque, conforme observado em sala de aula por meio, sobretudo, das práticas de Estágio Supervisionado desenvolvidas em escolas públicas e privadas, no Ensino Fundamental e Médio e ainda pelas análises dos materiais didáticos adotados pelas instituições de ensino realizadas na referida disciplina de um curso de Letras Português, em uma Universidade Multicampi no norte do Paraná, notamos que o valor atribuído à prática oral nem sempre atende às exigências atuais de ensino da língua materna, contempladas nos estudos produzidos na contemporaneidade e também previstas nos documentos oficiais supracitados. Nesse sentido, o objetivo deste trabalho é identificar as concepções e as limitações relacionadas à prática da oralidade em sala de aula, tendo em vista a seguinte questão: como a modalidade oral é compreendida por professores de Língua Portuguesa na rede básica de ensino e qual é o espaço destinado à oralidade, enquanto prática discursiva, em suas aulas?

Para tanto, fundamentados na perspectiva teórica de Marcuschi (1997) e Dolz e Schneuwly (2011), buscamos, primeiramente, situar teoricamente a modalidade da oralidade como uma prática discursiva, para, então, analisar o discurso de professores atuantes na área, tomando como instrumento de pesquisa a aplicação de um questionário. Desse modo, o artigo está organizado da seguinte forma: primeiramente, abordaremos a relação entre oralidade e escrita, para, então, localizarmos a oralidade enquanto prática discursiva. Em seguida, é necessário tecer algumas considerações sobre gêneros textuais ${ }^{4}$ e, especificamente, sobre gêneros orais. Por fim, analisamos as respostas dadas ao

\footnotetext{
${ }^{4}$ Reconhecemos as possibilidades de abordagem que compreendem os gêneros textuais e os gêneros discursivos de formas específicas, mas não buscamos discorrer sobre as perspectivas teóricas que abordam essas designações dos gêneros. Tomamos a definição de gêneros por meio de Marcuschi (2007, p. 19), que opta pela denominação de gêneros textuais, considerando-os como "fenômenos históricos, frutos do trabalho coletivo, que contribuem para "ordenar e estabilizar as atividades comunicativas do dia a dia".
} 
questionário aplicado para sete professores de língua portuguesa, que atuam em escolas públicas na cidade de Apucarana, PR. Dessa forma, esperamos contribuir para os trabalhos teórico-metodológicos que têm como temática a prática da oralidade no ambiente escolar.

\section{A relação entre as modalidades oral e escrita da linguagem}

Historicamente, percebemos que a sistematização do funcionamento da oralidade como expressão da linguagem é um movimento recente. Somente por volta do século XX é que observamos teóricos por parte da ciência linguística se dedicando ao estudo da fala, considerando as variantes existentes. Logo, podemos constatar que, a priori, a delimitação do oral como objeto de estudo condicionou-se a uma apresentação dicotômica entre oralidade e escrita.

Nesses estudos que se fundamentam na visão dicotômica, observa-se a escrita em sua estrutura complexa, formal e abstrata, ao passo que a fala corresponde à estrutura simples, informal e concreta, logo, menos valorizada. Essa visão impede a contemplação da oralidade enquanto forma de expressão autônoma, uma vez que concebe que a fala está condicionada à escrita.

Além disso, essa relação é construída estabelecendo critérios que permitem tornar a oralidade como uma manifestação da linguagem tomada pelo lugar do erro. Quando comparada à escrita, a oralidade se torna o lugar das "escórias" e "titubeios" (DOLZ; SCHNEUWLY, 2011) já que os estudiosos de linha mais tradicional consideram a fala sempre vinculada à escrita, de forma que a produção da fala é observada como uma reprodução fonética da escrita.

Marcuschi (1993 apud FÁVERO; ANDRADE; AQUINO, 2012, p.12) afirma que "os gramáticos imaginam a fala como lugar do erro, incorrendo no equívoco de confundir a língua como a gramática codificada [...]". Logo, é de grande valia explicar que essa confusão não corresponde à relação entre oralidade e escrita, 
mas sim à hierarquia constituída historicamente nas/pelas relações sociais, que caracterizou a oralidade como prática inferior à escrita, resultando na dificuldade de entender a oralidade enquanto prática discursiva autônoma.

Marcuschi (2010) defende que a oralidade e a escrita são práticas discursivas representadas por meio de modos apresentados cognitivo e socialmente. Para entendermos um pouco mais a respeito dessa complexa relação, precisamos observar que a língua ocorre por meio da interação verbal entre os falantes. Nessa perspectiva,

A verdadeira substância da língua não é constituída por um sistema abstrato de formas linguísticas nem pela enunciação monológica isolada, nem pelo ato psicofisiológico de sua produção, mas pelo fenômeno social da interação verbal, realizada através da enunciação ou das enunciações. A interação verbal constitui assim a realidade fundamental da língua (BAKHTIN/VOLOCHINOV, 2010, p. 127, grifo do autor).

A partir dessa concepção, um dos pressupostos utilizados para demonstrar a relação entre oralidade e escrita supera a contemplação das mesmas como modalidades de uso da língua e as colocam num parâmetro variável, que permite uma relação fundada num contínuo. Segundo Marcuschi (1997, p. 120),

[...] mais urgente (e relevante) do que identificar primazias ou supremacias entre oralidade e escrita, e mesmo mais importante do que observar oralidade e escrita como simples modos de uso da língua, é tarefa de esclarecer a natureza das práticas sociais que envolvem o uso da língua (escrita e oral) de um modo geral. Essas práticas determinam o lugar, o papel e o grau de relevância da oralidade e da escrita numa sociedade e justifica que a questão da relação entre ambas seja posta no eixo de um contínuo tanto sócio-histórico como tipológico.

Nesse sentido, compartilhamos da proposta de Marcuschi (1997) que considera as diferenças e as semelhanças entre oralidade e escrita dentro de um contínuo tipológico das práticas sociais. Considera-se tanto um contínuo tipológico quanto dos gêneros textuais, uma vez que essas práticas discursivas se correlacionam ao serem manifestadas por meio de estratégias que superam a 
aquisição do sistema linguístico e incorporam-se no funcionamento da língua mediante as condições de produção.

Esse contínuo entre as respectivas práticas discursivas pode ser observado durante o processo de comparação entre situações semelhantes das respectivas modalidades, pois mesmo manifestadas de modo diferente, possuem uma relação que pode ser contemplada dentro da perspectiva de uso, como podemos observar por meio dos gêneros textuais.

O contínuo dos gêneros textuais distingue e correlaciona os textos de cada modalidade (fala e escrita) quanto às estratégias de formulação que determinam o contínuo das características que produzem as variações das estruturas textuais-discursivas, seleções lexicais, estilo, grau e formalidade etc., que se dão num contínuo de variações, surgindo daí semelhanças e diferenças ao longo de contínuos sobrepostos (MARCUSCHI, 2010, p. 42, grifo do autor).

Dessa forma, oralidade e escrita possuem um contínuo, na medida em que a relação entre fala e escrita passa a ser vista mais por suas semelhanças, com vários gêneros envolvidos, do que pela rígida relação dicotômica. Nesse contínuo, as especificidades da oralidade e da escrita permitem que a língua seja acionada de acordo com as atividades sociointerativas do cotidiano. Uma vez que os falantes que estão inseridos na situação enunciativa, possuem a oportunidade de se adequarem ao momento da enunciação, ao passo que percebemos os mais variados contextos informais e formais tanto na oralidade como na escrita.

Considerando, pois, os limites tênues que envolvem a relação entre oralidade e escrita, abordaremos na próxima seção as especificidades da prática da oralidade, sobretudo, no que diz respeito ao seu tratamento no âmbito escolar, perspectiva fundamental para o presente trabalho.

\section{A prática da oralidade e o ensino de língua materna}


Os PCN (1998) orientam sobre a necessidade de a escola ensinar ao aluno a usar a linguagem oral. Além disso, reconhecem que tal linguagem demanda uma adequação aos contextos situacionais, já que justificam que não é o suficiente treinar apenas o nível mais formal da fala, uma vez que este não demanda todas as situações enunciativas. Esse documento também elenca algumas das inúmeras situações de exercício de cidadania, nos quais os alunos serão avaliados como, por exemplo, em entrevistas de emprego. Tendo em vista esses contextos, os PCN (1998) consideram a adequação da fala, bem como as características dos gêneros orais importantes para a formação do aluno.

As DCE de Língua Portuguesa (2008) também defendem a necessidade de a escola ensinar a linguagem oral, enquanto uma das práticas discursivas que possui grande participação no uso cotidiano da sociedade. É uma prática que permite a interação entre os falantes de determinada língua, correspondendo a uma linguagem natural do ser humano, que está, por sua vez, habituado a se comunicar através da fala.

Por conta deste e de outros fatores como a percepção do uso da oralidade nos mais variados contextos situacionais e a importância de sua adequação aos diferentes gêneros textuais, discorremos aqui, a respeito da prática da oralidade, a fim de refletir sobre o seu ensino nas aulas de língua portuguesa. No entanto, para isso, precisamos dar sentido a sua totalidade, o que nos leva a refletir sobre a oralidade enquanto objeto de estudo/ensino.

Além dos gêneros e recursos utilizados para a manifestação da linguagem oral, precisamos enfatizar a distinção constituinte da oralidade, que de acordo com Dolz e Schneuwly (2011) abrange dois tipos. O primeiro, relacionado à fala espontânea, que está vinculada à fala corrente. Se observarmos o oral puro, percebemos que sua produção é feita em tempo real da conversação. Já o segundo tipo de oralidade, aquele relacionado à escrita, é organizado primeiramente em forma de texto escrito para então ser reproduzido oralmente, 
o que torna a linguagem mais formal. Neste segundo caso, temos como exemplo a organização de um telejornal, uma palestra ou ainda um discurso político.

Considerando os PCN (1998), as DCE (2008), bem como o aporte teórico sobre oralidade, que contempla autores como Marcuschi (2010) e Dolz e Schneuwly (2011), compreendemos, pois, a oralidade como uma manifestação da linguagem fundamental para a expressão e compreensão de um povo, uma vez que possui uma finalidade social, que responde à necessidade de linguagem da sociedade, e que se agrupa em gêneros relativamente estáveis (DOLZ; SCHNEUWLY, 2011, p. 50).

Ademais, destacamos as colocações de Marcuschi (2010) que discorre sobre a presença da oralidade no cotidiano social utilizando os gêneros textuais, para demonstrar sua importância na expressão da sociedade. Assim, a prática da oralidade não consiste apenas no ato de falar por falar. Ela é integrada através de interações diversas entre os falantes, uma vez que a prática da oralidade nos leva a pensar sobre: $\mathrm{O}$ que falamos? Como falamos? Para que falamos? Essas questões nos possibilitam o entendimento do oral como constitutivo da linguagem.

Para Marcuschi (2010), a oralidade é considerada um fenômeno heterogêneo da linguagem, já que depende do contexto de produção e da situação comunicativa, pois essa heterogeneidade proporciona ao falante uma adaptação da linguagem. Podemos perceber exemplos de ajustes corriqueiros em situações cotidianas, como por exemplo, uma conversação ou até mesmo uma apresentação de trabalho.

Essa adaptação da linguagem ocorre por meio da inter-relação entre os falantes. Os recursos que podem ser utilizados por esses falantes na prática da oralidade são variáveis, já que o gesto, a ênfase prosódica e o contato visual podem facilitar a compreensão dos interlocutores no processo comunicativo, além de permitir uma adaptação imediata, de modo que o momento da enunciação dá licença para visualizar a reação do ouvinte. 
A partir de todos esses elementos, a presença da oralidade no ensino de língua materna ainda tem muita resistência, uma vez que se alimentou a ideia da fala como lugar destinado à informalidade e ao erro, conforme citado anteriormente. Para Figueiredo (2004, p.49 apud VASCONCELOS; CASAGRANDE, 2015, p.94), a pedagogia da oralidade é um produto tardio na cultura escolar, talvez porque, em termos de concepções teóricas, seja um objeto difícil de delimitar e, por isso, árduo em escolarizar.

Com o decorrer do tempo, percebemos o desenvolvimento de estudos que contemplam a oralidade como prática discursiva e como isso se materializa em documentos oficiais nacionais e estaduais que estabelecem as diretrizes gerais para o ensino básico, como os PCN (1998) e as DCE (2008). Nos PCN, encontramos a seguinte orientação:

no ensino-aprendizagem de diferentes padrões de fala e escrita, o que se almeja não é levar os alunos a falar certo, mas permitir-lhes a escolha da forma de fala a utilizar, considerando as características e condições do contexto de produção, ou seja, é saber adequar os recursos expressivos, a variedade de língua e o estilo às diferentes situações comunicativas [...] (PARANÁ, 1998, p. 31).

As DCE, por sua vez, demonstram algumas razões para ensinar a oralidade enquanto prática discursiva, considerando também as variantes linguísticas, ao passo que preza pela adequação da linguagem, pela situação enunciativa e reconhece o direito dos alunos de aprenderem a norma padrão.

No dia a dia da maioria das pessoas, a fala é a prática discursiva mais utilizada. Neste sentido, as atividades orais precisam oferecer condições ao aluno de falar com fluência em situações formais; adequar a linguagem conforme as circunstâncias (interlocutores, assunto, intenções); aproveitar os imensos recursos expressivos da língua e, principalmente, praticar e aprender a convivência democrática que supõe o falar e o ouvir (PARANÁ, 2008, p. 65).

O tratamento sobre as diferentes situações de uso indica que a oralidade envolve tanto a expressão de fatos e sentimentos, como a explicação clara e correta de temas científicos. Essa variedade de uso da língua proporciona um 
leque de possibilidades de uso dos gêneros orais. De acordo com Marcuschi (2010, p. 25), "a oralidade seria uma prática social interativa para fins comunicativos que se apresenta sob variadas formas ou gêneros textuais fundados na realidade sonora; ela vai desde uma realização mais informal à mais formal nos mais variados contextos de uso".

O trabalho com gêneros orais deve subsidiar, portanto, a oralidade enquanto prática discursiva, uma vez que deve permitir a compreensão do processo de adequação da linguagem. Quando observamos situações diferentes, como uma roda de conversa e uma comunicação oral, conseguimos indicar as características que limitam cada contexto de produção, o que nos leva, consequentemente, a adequar os recursos linguísticos e gestuais a cada situação, para que a interação se efetive.

Refletir sobre o ensino da oralidade nas aulas de língua portuguesa requer, pois, considerar a linguagem em uso, com base no desenvolvimento das competências comunicativas do aluno. Ao ter esta prática discursiva realizada por meio da inter-relação, observa-se a necessidade de abordar a oralidade de forma que possibilite ao aluno autonomia e criticidade, promovendo reflexão sobre a língua, ampliando sua capacidade comunicativa e levando-o a (re)conhecer os mais variados contextos discursivos.

Dolz e Schneuwly (2011, p.143) afirmam que "aprender a falar é apropriarse dos instrumentos para falar em situações de linguagem diversas, isto é, apropriar-se dos gêneros [...]". Faz-se necessário, desse modo, tratarmos, ainda que brevemente, sobre os gêneros textuais, já que sua presença no ensino de língua materna permite um direcionamento à reflexão da linguagem em uso, principalmente quando se trata de oralidade, considerando que os gêneros textuais se tornam um recurso fundamental para a apropriação da oralidade enquanto prática discursiva. É sobre isso que a próxima seção abordará. 


\section{Gêneros textuais: algumas especificidades dos gêneros orais}

Tomando como ponto de partida a prática da linguagem, os gêneros textuais são instrumentos fundamentais para a situação interativa, já que os locutores podem (re)conhecer um evento comunicativo por meio da instância do gênero. Tanto por meio da oralidade como da escrita, identificar os gêneros textuais nos permite entender as expectativas que permeiam locutor $\mathrm{e}$ interlocutor no processo de linguagem.

Para Dolz e Schneuwly (2011), é preciso considerar três dimensões essenciais para se pensar sobre o gênero textual como suporte de uma atividade de linguagem. Primeiramente, são observados os conteúdos e os conhecimentos ditos por meio dele; em segundo lugar, as estruturas comunicativas e semióticas compartilhadas por meio do texto; e, por fim, as configurações específicas de unidades de linguagem. Desse modo, de acordo com os autores (2011, p.143), "a ação de falar realiza-se com a ajuda de um gênero, que é um instrumento para agir linguisticamente", o que demonstra o funcionamento da linguagem.

No que se refere aos gêneros orais, são compreendidos pelos estudiosos, em linhas gerais, como instrumentos linguístico-discursivos, construídos por meio da língua falada. Esses gêneros apresentam características marcantes da linguagem oral, tanto de modo geral, sendo recorrente em todos os gêneros orais, quanto especificamente, caracterizando um gênero. Encontramos gêneros orais que demandam mais recursos não verbais, exigindo características da língua de forma sistemática, como por exemplo, o teatro, que utiliza recursos como a expressão facial, a ênfase prosódica e até mesmo a linguagem corporal.

De acordo com Travaglia (2013), considera-se gênero oral aquele que é construído tendo como suporte a voz humana, tanto produzido oralmente como passível de versões escritas, bem como os gêneros que possuem roteiros, mas primam pela realização oral do mesmo. Encaixando-se nesta classificação, temos os gêneros: notícias faladas nos telejornais e rádios, as representações de peças 
teatrais e os filmes. Nesse sentido, podemos observar os diferentes graus de oralidade, considerando que existem gêneros produzidos para a realização oral que possuem uma versão escrita e possuem menos características orais que um gênero tipicamente oral.

Marcuschi (2010, p. 40) propõe uma distribuição de quatro gêneros textuais (Conversação Espontânea, Artigo Científico, Notícia de TV e Entrevista publicada na Veja), na qual considera o meio de produção e a concepção discursiva, caracterizando seus domínios. Dessa forma, podemos observar que, segundo o autor, uma conversação espontânea é um gênero textual, que possui um meio de produção sonoro, bem como uma concepção discursiva oral, marcando então um domínio prototípico. Notamos, também, que uma notícia de TV possui meio de produção sonoro, mas sua concepção discursiva é escrita, marcando um domínio misto, em que meio de produção e concepção discursiva são modalidades diversas.

Essa proposta de Marcuschi (2010) permite compreender a relação fala e escrita por meio do contínuo dos gêneros textuais, e nos leva a refletir que os gêneros orais não são assim agrupados apenas por conta de uma classificação prototípica, mas eles também podem possuir uma classificação mista. Nota-se, pois, que na proposta do contínuo, o fator determinante não é a modalidade escrita nos gêneros orais, mas os usos prioritários da fala que os caracterizam.

Já para Travaglia (2013), a pesquisa sobre os gêneros orais abrange a distinção entre as atividades sociais e os gêneros textuais, bem como a função dos gêneros orais nas esferas discursivas. Nas palavras do autor,

podemos estabelecer que a atividade social é o que alguém está fazendo, para atingir determinado objetivo, enquanto o gênero é um instrumento linguístico-discursivo devidamente estruturado, criado em uma esfera de atividade humana por uma comunidade discursiva, como uma forma eficiente de realizar a atividade em que o gênero tem um papel essencial (TRAVAGLIA, 2013, p. 4, grifo do autor). 
A função social do gênero decorre, então, da esfera discursiva para a qual serve de instrumento. Segundo Travaglia (2013), os gêneros orais são elaborados em esferas de atividades humanas, sendo que cada esfera discursiva possibilita a produção de diferentes gêneros orais, como por exemplo, a esfera das relações do dia a dia, que abarca gêneros orais como fofoca, cantigas de ninar, conselho, recados, discussões, entre outros.

É importante destacarmos que Travaglia (2013) não inseriu alguns elementos em sua listagem de atividades humanas nas quais os gêneros textuais são produzidos, justificando que os consideram atividades e os mesmos são arrolados enquanto gêneros orais. Dentre esses elementos encontramos conversações que, segundo o autor, correspondem à atividade humana, mas para Marcuschi (2010) é um gênero textual. Observamos aqui, uma sutil diferença entre as perspectivas de ambos os autores a respeito dos gêneros orais ${ }^{5}$.

Posto isso, analisaremos as respostas dos questionários aplicados aos professores da rede básica pública de ensino, com a finalidade de compreender o que entendem por oralidade, bem como o espaço que destinam a essa prática no ambiente escolar.

\section{Considerações sobre a oralidade em sala de aula: a perspectiva de professores da rede básica pública de ensino}

O corpus de análise desta pesquisa é composto por sete questionários respondidos por professores de língua portuguesa da rede básica pública de ensino, da cidade de Apucarana-PR. Os docentes participantes lecionam em escolas públicas do município, em regime de trabalho temporário, com poucos

\footnotetext{
${ }^{5}$ Para o estudo dos gêneros orais, buscamos novas maneiras de compreendê-los, por meio do intermédio de diferentes concepções teóricas, que de certa forma, complementam-se.
} 
anos de atuação profissional. Para a pesquisa em questão, dentre os colégios do município, o Núcleo de Educação Básica determinou três para o desenvolvimento da pesquisa, dois em regiões mais afastadas do centro da cidade e um, que embora mais central, recebe alunos de áreas mais periféricas. Apesar de o quadro de professores de língua portuguesa ser maior do que a relação aqui apresentada nos três colégios, pontuamos que apenas sete se dispuseram a participar da pesquisa.

O questionário, aplicado no ano de 2016, faz parte do projeto de pesquisa intitulado "Gêneros Discursivos em sala de aula: propostas de estudo e de didatização"6. Este instrumento teve como objetivo principal fazer um levantamento, de caráter diagnóstico, de alguns aspectos do ensino e da aprendizagem de língua materna na educação básica.

Dentre os elementos levantados nas dezoito questões, foram inseridas seis que contemplam especificamente a prática da oralidade no ambiente escolar, no que diz respeito a sua importância, bem como sua relação com a escrita e o trabalho com gêneros escritos e orais. Os questionários precisavam ser respondidos impreterivelmente na presença do pesquisador, por conta de algumas especificidades da pesquisa do projeto. Dessa forma, os professores que aceitaram participar responderam ao questionário na presença de um participante do projeto, contudo, não houve qualquer interferência em suas respostas.

Metodologicamente, organizamos a análise a partir de três categorias, a partir das relações levantadas na fundamentação teórica7: (a) a relação entre oralidade e escrita; (b) ensino da oralidade; e (c) gêneros orais. Para discorrermos sobre as respostas, manteremos o sigilo dos participantes e, para isso, usaremos uma identificação numérica. Dessa forma, o professor terá a

\footnotetext{
6 Projeto de Pesquisa coordenado pela Profa Dra Neluana Leuz de Oliveira Ferragini, na Universidade Estadual do Paraná, campus de Apucarana (2016-2018).

${ }^{7}$ Desse modo, as perguntas não serão apresentadas na ordem que aparecem no questionário, mas, sim, considerando os itens norteadores para os agrupamentos.
} 
mesma identificação em todas as questões, permitindo-nos observar a perspectiva de cada participante através da relação entre as respostas.

\subsection{Relação entre oralidade e escrita}

A décima sétima pergunta do questionário foi: "Para você, oralidade e escrita possuem alguma relação? Qual?". Ao justificarem a relação entre oralidade escrita, quatro professores aproximam suas respostas, uma vez que usam argumentos que indicam que uma modalidade está inserida na outra.

Professor 1: Sim, muitos alunos escrevem da maneira como falam. (grifo nosso)

Professor 2: Uma está inserida na outra. (grifo nosso)

Professor 5: Sim, uma depende da outra, pois a escrita tem a função de representar os sons da fala. (grifo nosso)

Professor 6: Sim. Pois tudo que falamos pode ser escrito. (grifo nosso)

Para esses professores, a relação entre oralidade e escrita pode ser observada por meio de uma representação, uma vez que cabe à escrita representar os sons da fala. Observamos que há uma concepção que considera uma prática discursiva dependente da outra, neste caso, a oralidade está sujeita à escrita, tornando oportuna a noção de subordinação, logo considerando uma prática como mais importante que a outra. Neste sentido, salientamos que não consideramos errado afirmar que a escrita representa a fala, no entanto, a relação entre ambas as modalidades não se limita apenas à transcrição ortográfica da fala. Pensar assim nos leva a considerar a fala condicionada à escrita, logo, identificando-a como lugar do erro. Segundo Dolz e Schneuwly (2011), pensar sobre fala, partindo dos parâmetros do discurso organizado da escrita é condenar-se a ver a oralidade apenas como hesitações e impropriedades. 
Um exemplo bem marcante dessa concepção pode ser observado no argumento do Professor 1, "muitos alunos escrevem da maneira como falam". Tal comentário sobre a relação entre oralidade e escrita é breve, mas pode revelar que para ele escrever da forma que fala corresponde a repetir os "erros" e "acertos" presentes na fala. Observamos que, nessa resposta, os "erros" têm um peso maior para o professor, já que ele não utiliza, por exemplo, o termo "indivíduos", caracterizando essa relação como natural da linguagem, mas usa o termo "alunos", que durante o processo de aprendizagem podem apresentar produções escritas passíveis de incorreções, dado o discurso pedagógico no qual estão inseridos.

Além disso, três professores também possuem respostas aproximadas ao discorrerem sobre a relação entre oralidade e escrita como complementares.

Professor 3: Sim, como já disse anteriormente oralidade e escrita se casam (escrita e fala). (grifo nosso)

Professor 4: Oralidade e escrita trabalha-se junto. Sim a relação de ler e escrever (ouvir e relatar). (grifo nosso)

Professor 7: Sim, são complementares, uma complementa a outra e ajuda a visualizar a totalidade da aprendizagem. (grifo nosso)

Notamos que a proximidade entre as respostas desses três professores é identificada, primeiramente, por meio da compreensão da oralidade e da escrita enquanto modalidades distintas, que são relacionadas de forma que uma se soma a outra. Observamos que os professores argumentaram sobre essa relação, colocando oralidade e escrita em um mesmo nível de importância, uma vez que não dizem que uma modalidade "depende" da outra, mas que ambas as práticas se complementam.

O sentido metafórico na resposta do Professor 3, "oralidade e escrita se casam", evidencia uma perspectiva que reconhece essas práticas em sua totalidade, bem como sua contribuição social. Além disso, a resposta do Professor 7 também segue essa visão das práticas discursivas enquanto modalidades que 
se complementam, uma vez que argumenta explicitamente que "uma complementa a outra".

Ao afirmar que "oralidade e escrita trabalha-se junto", o Professor 4 também identifica essas práticas enquanto modalidades que se complementam, no entanto, seus exemplos não condizem com a relação que identificou, já que ele explicita, entre parênteses, as ações de "ler e escrever" e em seguida "ouvir e relatar". Dessa forma, mesmo considerando a relação entre ambas as práticas, o professor demonstra que essa relação corresponde à noção de que é possível produzir textos orais e escritos, enunciando que existe interação na produção escrita e delimitando a interação da produção oral na ordem do "relatar", já que considera a produção oral enquanto práticas de "ouvir e relatar". Posto isso, notamos que tal professor corrobora a relação entre oralidade e escrita, mas não identifica nitidamente a forma que a mesma acontece.

Compreendemos, também, que os Professores 3, 4 e 7 identificaram oralidade e escrita enquanto modalidades de uso da linguagem. Esse é o caminho para a compreensão dessas modalidades enquanto práticas discursivas, extremamente importante no nosso cotidiano atualmente. No entanto, não é o suficiente, já que para Marcuschi (1997) entender a importância da natureza que envolve o uso da linguagem oral e escrita é mais urgente que considerá-las como simples modos de uso da língua.

Ressaltamos, por fim, dentre as respostas dos sete professores, que não houve menção sobre a relação de contínuo entre oralidade e escrita, conforme apontado anteriormente, a partir de Marcuschi (1997). Para os professores entrevistados, a relação se dá, pois, a partir da noção de modalidade distintas que se complementam ou funcionam juntas, e não pelos usos prioritários de fala que caracterizam os gêneros orais.

\subsection{Ensino da oralidade}


A segunda questão do questionário foi formulada de modo que os professores pudessem assinalar a frequência com que trabalham com a prática da oralidade e explicassem de que forma isso acontece. Transcrevemos a questão a seguir:
A prática da oralidade se faz presente em suas aulas?
( ) Sempre ( ) Às vezes ( ) Raramente ( ) Nunca
De que forma?

Nessa questão, dos sete professores, seis assinalaram que a prática da oralidade sempre se faz presente em suas aulas e apenas um professor marcou a alternativa "às vezes". Entretanto, ao explicitarem a forma que a oralidade está presente nas aulas de língua portuguesa, as respostas tiveram variações significantes, como podemos ver a seguir.

Professor 1: Leituras e debates. (grifo nosso)

Professor 2: Através de leituras didáticas, pedagógicas, debates com questões atuais, apresentações de trabalhos em grupos, entre outros. (grifo nosso)

Professor 3: Estamos sempre fazendo rodas de leituras, debates com questões atuais, apresentações de trabalhos em grupos, entre outros. (grifo nosso)

Professor 4: Leitura de textos e Oralidade nas aulas de Língua Portuguesa são muito interessantes trabalhar os Gêneros Discursivos. (grifo nosso)

Professor 5: Através das explicações, leituras, apresentações. (grifo nosso)

Professor 6: Os alunos relatam fatos vivenciados; relatam o que entenderam do texto lido; e também discutem sobre algo que aconteceu (notícias). (grifo nosso)

Professor 7: Explanando os conteúdos, fazendo debates, interagindo com os alunos através de diálogos sobre os assuntos propostos. (grifo nosso)

As respostas acima apontam para alguns procedimentos metodológicos de cada professor, já que conseguimos perceber quais alternativas escolhem para o trabalho com a prática da oralidade em sala, tendo em vista que são possíveis diversas formas de inserir a oralidade no ambiente escolar. Desse modo, observamos que mesmo em situações diferentes, incluindo questões 
metodológicas, perfil das turmas dos professores e até mesmo suas preferências, a maioria dos professores aproximou suas respostas, ao decidirem por atividades parecidas ou até mesmo iguais.

Dos setes professores, quatro inseriram atividades de leituras (Professores 1, 2, 3 e 5), variando apenas a maneira como são desenvolvidas, como por exemplo, leituras didáticas, pedagógicas, bem como rodas de leituras. Entendemos que essa prática de leitura diz respeito à leitura de textos em voz alta, pelos alunos, prática muito limitada, uma vez que não supre o trabalho com oralidade em sala, pois muitas vezes se trata somente de textos escritos, que não fazem parte de gêneros orais e dizem respeito apenas à reprodução oral. Sequer se encaixam na concepção de gênero oral, tal como vimos em Travaglia (2013), quando considera os gêneros orais como aqueles que têm a voz humana como suporte, mas que devem ter uma base escrita como os telejornais e filmes, ou seja, textos preparados para serem realizados oralmente.

Notamos que cinco professores (Professores 1, 2, 3, 6 e 7) aproximam suas respostas ao considerarem o debate como forma de desenvolver a prática da oralidade em sala de aula. Desse modo, observamos que esses professores entendem a prática da oralidade em sala como possibilidade de expressão oral, partindo de assuntos variados para o desenvolvimento da mesma por meio da exposição de argumentos para se defender determinado ponto de vista, considerando, portanto, as condições de produção desse gênero. Observamos, entretanto, que o questionário não é suficiente para avaliarmos se o trabalho com o gênero "debate" contemplaria uma preparação específica para um desempenho satisfatório, nem mesmo se os procedimentos didáticos seriam significativos para que o aluno colocasse em prática em seu cotidiano, a seleção e organização de argumentos ao entrar em contato com gêneros próximos ao debate. Por isso, ressaltamos apenas a importância desse gênero ser citado pelos professores, mas sem garantir que o trabalho o considere, de fato, como uma prática discursiva. 
Apenas o Professor 2 colocou "textos diversificados em outros contextos", deixando a resposta ampla, sem delimitar a tipologia, o gênero textual ou algum texto que é trabalhado para sabermos se esses textos são orais ou escritos. 0 Professor 3 também é o único que inseriu "apresentações de trabalhos em grupos", considerando tanto a importância da oralidade quanto da prática de trabalho em grupo.

Além disso, o Professor 6 inseriu o gênero "relato" tanto de experiências pessoais quanto de leitura, considerando um gênero que tem grande influência no trabalho com a oralidade, já que esse possui características marcantes dessa prática discursiva, além de se fazer presente no nosso cotidiano.

Observamos que os Professores 5 e 7 consideraram explicações de conteúdos como trabalho com a prática da oralidade, no entanto, não é especificado se são os alunos que explanam os conteúdos ou os professores.

O Professor 4, por sua vez, distancia-se das respostas dos demais professores, ao passo que comenta sobre leitura, oralidade e gêneros discursivos na aula de língua portuguesa, mas sua resposta não é coerente com a questão e ainda não possui uma significação lógica. 0 mais provável é que o professor estava apenas preenchendo o espaço.

Considerando todas as respostas dessa questão, percebemos que os professores não contemplaram o estudo da prática da oralidade em si, apesar de mencionarem a presença desta prática em suas aulas. Não demonstraram trabalhar suas características, adequações aos gêneros orais, bem como importância social, tal como demanda os estudos que fundamentam as diretrizes atuais para o ensino dessa modalidade ${ }^{8}$. Conforme exposto anteriormente, de acordo com Marcuschi (2010), a oralidade corresponde a uma prática social

\footnotetext{
${ }^{8}$ Ademais, as respostas dessa questão serão importantes para a análise encontrada no subitem seguinte, uma vez que este abordará os gêneros que os professores utilizam ou gostariam de trabalhar em sala. Faremos uma relação entre a forma que os professores inserem a oralidade em suas aulas e os gêneros que aparecerão na questão posterior.
} 
interativa que é apresentada por meio dos gêneros textuais, variando desde a realização mais informal até a mais formal.

A décima segunda questão do questionário, por sua vez, foi elaborada de modo que os professores pudessem apresentar considerações sobre a prática de oralidade em sala de aula, uma vez que a questão postulada é a seguinte: "Como professor, qual a importância da prática da oralidade em sala de aula?"

De modo geral, verificamos que os professores atribuem importância à prática de oralidade, discorrendo sobre o desenvolvimento individual/cognitivo dos alunos. Mesmo com a variação dos discursos, apresentando raciocínios diferentes, ainda observamos uma prioridade para a cognição, como podemos ver nas respostas a seguir.

Professor 1: Muito importante pois ajuda na comunicação e formação de ideias (grifo nosso)

Professor 2: De grande importância, pois auxilia na interação social, na expressão oral, no aprendizado e principalmente na construção das ideias. (grifo nosso)

Professor 3: Desenvolve-se uma boa leitura, com isso temos boa interpretação, bom vocabulário. (grifo nosso).

Professor 4: A importância de levar o conteúdo de uma forma mais compreensível e Direta-Objetiva usando a oralidade em sala conseguimos transformar a aprendizagem em instrumento de ensino com mais facilidade. (grifo nosso)

Professor 5: Desenvolver no aluno a capacidade cognitiva. (grifo nosso)

Professor 6: Na minha prática docente é fundamental, pois os alunos conseguem desenvolver a sequenciação de ideias, desenvolve também memória, raciocínio. (grifo nosso).

Professor 7: Muito importante, pois muitos alunos aprendem mais ouvindo a explicação, outros copiando (escrevendo), e outros ainda visualizando a imagem e ouvindo o texto, como em vídeos. (grifo nosso)

Dessa forma, constatamos uma prioridade para o desenvolvimento intelectual próprio de cada aluno, sobretudo, pelas colocações do Professor 2 que elenca outras contribuições, mas realça a construção de ideias, bem como nos Professores 5 e 6 que abordam apenas o desenvolvimento em questão. 
Notamos também que os professores mencionaram outras contribuições, como por exemplo, os Professores 1 e 2 que aproximam suas respostas ao considerarem a "comunicação" e "expressão oral", uma vez que se torna possível a percepção de que a oralidade em sala de aula permite um desenvolvimento que leve os alunos a transmitirem informações de uma forma aprimorada.

De acordo com a resposta do Professor 3, deparamo-nos com uma concepção de linguagem como expressão do pensamento, já que para ele a leitura e a interpretação influenciam o aprimoramento do vocabulário, levandonos a considerar uma noção de que se o indivíduo pensa bem, logo falará bem.

Além disso, observamos que o Professor 2 insere a interação social como um desenvolvimento vinculado à prática de oralidade. Entretanto, os Professores 4 e 7 acabaram desviando suas respostas do foco da questão, uma vez que 0 Professor 4 se pronuncia sobre a importância de transmitir o conteúdo de uma forma mais compreensível. No entanto, sua resposta segue com argumentos que interferem na compreensão, permitindo-nos observar apenas a relação do professor com a preocupação de transmissão de conteúdo.

Ademais, o Professor 7 ponderou a importância da prática da oralidade considerando os níveis de aprendizagem, elencando a maneira que os alunos adquirem conhecimento, variando de acordo com o perfil de cada um.

Embora todos os professores tenham concordado com a importância da prática da oralidade no ensino e tenham especificado algumas contribuições, notamos que nenhum professor mencionou a importância de adequar a fala de acordo com as diferentes situações comunicativas, a fim de reconhecer os gêneros textuais, suas particularidades, bem como formalidades e informalidades presentes na prática oral.

\subsection{Gêneros textuais orais}


A quarta pergunta do questionário foi formulada da seguinte maneira: "Quais os gêneros escritos e orais que mais utiliza ou gostaria de trabalhar em sala?"

Inicialmente, percebemos que as respostas são heterogêneas, posto que os professores listam gêneros diversos, que dificilmente são inseridos nas demais respostas (com ressalva dos contos e das fábulas), por conta da preferência dos professores, dado que evidenciamos uma recorrência desses gêneros em suas respostas. Posto isso, a maioria dos professores menciona apenas gêneros escritos, como podemos observar nas respostas a seguir.

Professor 1: Conto, crônica, texto dramático, artigo de opinião. (grifo nosso)

Professor 2: Crônica, fábula, conto, romance e jornalistas.

Professor 3: Notícias, reportagens, contos, fábulas, poesias, entre outros.

Professor 4: Os gêneros escritos e orais mais utilizados são textos de Reportagem de jornais e revistas.

Professor 5: Gibis, leituras de textos no livro didático como cartas, artigos, depoimentos, jornal. (grifo nosso)

Professor 6: Trabalho: poesias; textos narrativos; contos; textos informativos; quadrinhas; fábulas; história em quadrinhos.

Professor 7: Gênero narrativo; gênero descritivo; gênero (textos publicitários -propaganda).

O gênero conto é apontado por quatro professores (Professores 1, 2, 3 e 6) e três professores lembram-se das fábulas (Professores 2, 3 e 6), demonstrando maior recorrência de gêneros de tipologia narrativa, que possuem circulação, na maioria das vezes, por conta do trabalho com o mundo maravilhoso e, possivelmente, pela forma que as fábulas são contadas, geralmente por meio do uso de recursos orais e gestuais que prendem a atenção do interlocutor. Acrescentamos também, que correspondem a gêneros frequentemente abordados nos materiais didáticos.

Ao analisarmos quais gêneros são trabalhados em sala de aula, verificamos o espaço limitado destinado à prática da oralidade em sala de aula, 
já que encontramos uma média de doze gêneros escritos, distribuídos entre os sete professores por meio da seguinte forma: crônica (Professores: 1 e 2); artigo de opinião/artigo (Professores 1 e 5); poesia/quadrinha (Professores 3 e 6); história em quadrinhos/gibi (Professores 5 e 6); romance (Professor 2); notícia (Professor 3); reportagem (Professor 3); carta (Professor 5) e propaganda (Professor 7).

Desse modo, apenas dois gêneros predominantemente orais foram lembrados e divididos entre apenas dois professores, sendo o texto dramático (Professor 1) e depoimentos (Professor 5). Compreendemos, assim, que a prioridade por gêneros escritos promove praticamente a exclusão do trabalho com gêneros orais.

Já a resposta do Professor 7, "gênero narrativo; gênero descritivo; gênero (textos publicitários - propaganda)", nos leva a entender uma concepção de gêneros textuais atribuída às tipologias, deixando uma resposta bastante aberta, na qual o professor parece afirmar que sempre trabalha todos os textos que pertencem aos tipos: narrativo e descritivo, bem como os textos publicitários, identificados pelo mesmo como propagandas. Além disso, demais professores elencaram tipologias como, por exemplo, textos narrativos e textos informativos (Professor 6).

A partir dessas considerações, chamamos atenção para a análise da segunda questão do questionário, vista anteriormente, no item 5.2: "A prática da oralidade se faz presente em suas aulas?". Nas respostas, percebemos que a maioria dos professores assinalou "sempre" e apenas um "às vezes", mas ao explicarem a forma que a oralidade é trabalhada, responderam por meio de leituras.

Compreendemos que essas leituras em sala correspondem à leitura de textos em voz alta, textos esses pertencentes aos gêneros escritos, uma vez que os professores que sempre trabalham oralidade, conforme apontado na questão 2, listaram apenas gêneros escritos, na questão 4, com exceção dos Professores 
1 e 5, que inseriram apenas um gênero oral, no entanto, o trabalho contínuo com a prática da oralidade em sala exige mais gêneros orais, apenas um não é o suficiente.

\section{Considerações finais}

Embora a prática da oralidade se faça presente nas salas de aula, na maioria das vezes não é contemplada enquanto prática discursiva, que precisa ser ensinada e desenvolvida durante as aulas de Língua Portuguesa. Por isso, propomo-nos, nesta pesquisa, a identificar as concepções e as limitações relacionadas à prática da oralidade em sala de aula, tendo em vista a seguinte questão: como a modalidade oral é compreendida por professores de Língua Portuguesa na rede básica de ensino e qual é o espaço destinado à oralidade, enquanto prática discursiva, em suas aulas?

Compreendemos que a análise dos questionários aplicados aos professores da rede básica de ensino mostra-nos, ainda que parcialmente, a realidade da educação, na qual o ensino-aprendizagem da oralidade enquanto prática discursiva é tardio e pouco realizado. Enfatizamos que esse resultado pode ser decorrente de uma carência de formação sobre essa modalidade e de materiais teórico-metodológicos voltados para a prática da oralidade em sala. Podemos perceber isso pelos professores demonstrarem uma concepção superficial de oralidade e um trabalho que não privilegia a prática de produção oral, já que ao ser solicitada a indicação dos gêneros escritos e orais que são trabalhados em sala de aula, são indicados gêneros escritos, em sua maioria.

Considerando tais obstáculos, constatamos a necessidade da criação de espaços que promovam pesquisas sistemáticas sobre a prática da oralidade, que tenham efeito enquanto ação formativa dos professores que atuam no ensino fundamental e médio. Desse modo, a partir de uma postura reflexiva, os 
professores podem promover com seus alunos uma prática efetiva de ensinoaprendizagem de gêneros orais e suas adequações aos contextos situacionais.

Posto isso, ressaltamos, por fim, a possibilidade de continuidade da pesquisa em trabalhos futuros, por meio da elaboração de uma proposta de prática da oralidade que seja discutida, produzida e aplicada pelos e para os professores, que contribua para o desenvolvimento da competência comunicativa dos alunos.

\section{REFERÊNCIAS}

BAKHTIN, Mikhail (Volochinov). Marxismo e filosofia da linguagem. Trad. de Michel Lahud e Yara Frateschi. 14 ed. São Paulo: Hucitec, 2010.

BRASIL. Parâmetros Curriculares Nacionais: $3^{\circ}$ e $4^{\circ}$ ciclos do Ensino Fundamental: língua portuguesa. Brasília: Ministério da Educação e do Desporto, Secretaria da Educação Fundamental, 1998.

DOLZ, Joaquim. SCNEUWLY, Bernard. O oral como texto: como construir um objeto de ensino. In: Gêneros orais e escritos na escola. São Paulo: Cortez, p. 125-155, 2011.

FÁVERO, Leonor Lopes; ANDRADE, Maria Lúcia C.V.O; AQUINO, Zilda G.O. Oralidade e escrita: perspectivas para o ensino de língua materna. 8. ed. São Paulo: Cortez, 2012.

MARCUSCHI, Luiz Antônio. Oralidade e escrita. Signótica, Goiás, v.9, n.1, p. 119- 145, jan/dez, 1997.

Cortez, 2010.

. Da fala para a escrita: atividades de retextualização. 10.ed. São Paulo:

PARANÁ. Secretaria de Estado da Educação do Paraná. Departamento de

Educação Básica. Diretrizes Curriculares da Educação Básica - Língua Portuguesa. Paraná, 2008.

TRAVAGLIA. Luiz, Carlos. Gêneros orais - Conceituação e caracterização. In Anais do SILEL, v.3, n.1. XIV Simpósio Nacional de Letras e Linguística e IV Simpósio Internacional de Letras e Linguística. Uberlândia: EDUFU, 2013, p. 1 a 8. Disponível em:

<http://www.ileel.ufu.br/anaisdosilel/wpcontent/uploads/2014/04/silel2013_15 28.pdf. Acesso em: 17 de agosto de 2017. 
VASCONCELOS, Maria Lucia. CASAGRANDE, Nancy. Oralidade e ensino: o difícil caminho da teoria à prática. Todas as letras. São Paulo, v. 17, n.1, p. 91-102, jan/abr. 2015. 